\title{
Estudo estereológico comparativo de complexos cumulus-ovócito aspirados de folículos durante o ciclo estral em bovinos
}

\author{
[Comparative stereological study of cumulus-oocyte complexes aspirated from follicles \\ during the estrous cycle in bovine] \\ A.M. Calado ${ }^{1}$, E. Rocha ${ }^{2}$, A. Colaço ${ }^{1}$, M. Sousa ${ }^{2}$ \\ ${ }^{1}$ Departamento de Ciências Veterinárias - Universidade de Trás-os-Montes e Alto Douro \\ Apartado 202, 5001 Vila Real Codex, Portugal \\ ${ }^{2}$ Instituto de Ciências Biomédicas de Abel Salazar - Universidade do Porto, Portugal
}

\begin{abstract}
RESUMO
Realizou-se uma análise estereológica comparativa de complexos cumulus-ovócito (COCs) de bovino da raça Holtein-Friesian aspirados de folículos antrais pequenos (com diâmetro de 1-4mm) e médios (com diâmetro de $4-8 \mathrm{~mm}$ ) durante as fases de metaestro, diestro e de proestro. Foram estimados o volume médio dos COCs, dos ovócitos (com e sem zona pelúcida), dos núcleos dos ovócitos e das células foliculares e seus respectivos núcleos. Estimou-se a espessura da zona pelúcida e calculou-se a percentagem relativa da freqüência dos diferentes tipos de células foliculares encontradas no cumulus. Os folículos pequenos apresentaram crescimento acelerado e sem sincronia entre o volume do citoplasma e o do núcleo. No folículo médio ocorreu expansão harmoniosa núcleo-citoplasmática. Identificaram-se três populações de células foliculares ( $\mathrm{C} 1, \mathrm{C} 2$ e C3), cuja distribuição na massa do cumulus é independente de sua posição relativamente ao ovócito. Durante o ciclo estral, as células $\mathrm{C} 1$ foram progressivamente substituídas por $\mathrm{C} 2$ e estas, por $\mathrm{C} 3$.
\end{abstract}

Palavras-chave: bovino, célula folicular, ciclo estral, COC, estereologia

\begin{abstract}
A comparative stereological analysis was performed in cumulus-oocyte complexes from HolsteinFriesian cows, aspirated from small (with diameter of 1-4mm) and medium (with diameter of 4-8mm) antral follicles during metestrous, diestrous and proestrous. The mean volumes of COCs, oocytes (with and without zona pellucida), nucleus of the oocyte, as well as the volumes of the follicular cells and their nucleus were estimated. The mean thickness of the zona pellucida and the relative percentage of the three follicular cell types in the cumulus mass were also obtained. Small antral follicles had an accelerate growth without synchrony between the volume of the oocyte and the respective nucleus, while in medium antral follicles an harmonious nucleus-cytoplasmic expansion was observed. These follicular cell populations were classified in their types, C1, C2 and C3, which the distribution in the cumulus mass appeared to be independent to their position in relation to the oocyte. During the estrous cycle, cell type C1 progressively developed to $C 2$, and this one to $C 3$.
\end{abstract}

Keywords: bovine, follicular cell, estrous cycle, COC, stereology

Recebido para publicação em 1 de abril de 2004

Recebido para publicação, após modificações, em 17 de novembro de 2004

E-mail: anacalad@utad.pt 


\section{INTRODUÇÃO}

Os complexos cumulus-ovócito de bovino (COCs), aspirados de folículos imaturos, constituem uma fonte importante de material biológico para o estudo da esteroidogênese, da maturação e da fecundação in vitro, bem como para a produção de animais de valor comercial. A produção in vitro de embriões de bovino a partir de complexos imaturos atinge normalmente a taxa de 30\% (Shamsuddin et al., 1996). Este sucesso limitado pode ser parcialmente atribuído aos métodos de seleção dos COCs, baseados exclusivamente em parâmetros morfológicos avaliados ao estereomicroscópio, tais como a morfologia do ooplasma e do cumulus, o tamanho do folículo e do ovócito, e o grau de atresia folicular. Os COCs com massa de cumulus compacta e constituída por numerosas camadas de células foliculares, e com um ovócito de ooplasma homogêneo, apresentam maior capacidade de desenvolvimento, contrastando com os COCs de cumulus expandido e ooplasma heterogêneo (De Loos et al., 1989, 1991).

O processo de seleção de ovócitos e de COCs de bovino para utilização em diferentes áreas da reprodução apresenta dificuldades, atribuídas à escassez de informações acerca das características morfológicas que melhor reflitam a capacidade de desenvolvimento dos gametas. Desse modo, uma análise morfológica quantitativa rigorosa (estereologia) poderá fornecer elementos fundamentais para ajuizar acerca das características mais vantajosas dos COCs.

Até a presente data, a aplicação das ferramentas estereológicas exatas sem viés limitam-se a alguns estudos em folículos de mamíferos, nomeadamente em roedores (Bagger et al., 1989, 1993; Bagger, 1993), ovinos (Lundy et al., 1999), primatas (Miller et al., 1997) e humanos (Dhar et al., 1996). Recentemente, fez-se uma caracterização esterológica dos complexos cumulus-ovócito imaturos de bovino, aspirados de folículos antrais pequenos (1-4mm) e médios (4-8mm) durante o ciclo estral (Calado et al., 2001, 2003a,b). Os objetivos deste trabalho foram: 1- realizar um estudo estereológico comparativo dos COCs de Bos taurus, 2- comparar algumas características morfológicas, nomeadamente volume dos COCs, dos ovócitos e respectivos núcleos e das células foliculares e respectivos núcleos, e espessura da zona pelúcida (ZP) dos COCs e 3- avaliar a homogeneidade do cumulus.

\section{MATERIAL E MÉTODOS}

Foram colhidos ovários de 63 animais da raça Holstein-Friesian no matadouro local. Os ovários foram selecionados de acordo com o padrão morfológico que permite identificar a fase do ciclo estral, com base na presença/cor, tamanho e vascularização do corpo hemorrágico/corpo lúteo (Ireland et al., 1979) (Fig. 1). Os ovários foram imediatamente transportados para o laboratório onde se aspirou o conteúdo dos folículos de 1$4 \mathrm{~mm}$ e de $4-8 \mathrm{~mm}$ de diâmetro, conforme descrito por Calado et al. (2001, 2003a,b) (Tab. 1). Selecionaram-se os COCs que apresentavam massa completa e compacta de células do cumulus e ooplasma com aspecto uniforme (Fig. 2) (Leibfried e First, 1979; Madison et al., 1992; Blondin e Sirard, 1995).

Tabela 1. Número de animais, de complexos cumulus-ovócito (COCs) e de células foliculares amostradas por COC e por campo de amostragem nas duas classes de diâmetros foliculares ao longo do ciclo estral em Bos Taurus

\begin{tabular}{|c|c|c|c|c|c|}
\hline $\begin{array}{l}\text { Diâmetro } \\
\text { folicular } \\
(\mathrm{mm})\end{array}$ & $\begin{array}{c}\text { Fase } \\
\text { do ciclo }\end{array}$ & $\begin{array}{c}\mathrm{N}^{\mathrm{o}} \text { de } \\
\text { animais }\end{array}$ & $\begin{array}{l}\mathrm{N}^{\mathrm{o}} \mathrm{de} \\
\mathrm{COCs}\end{array}$ & $\begin{array}{c}\mathrm{N}^{\mathrm{o}} \text { de células } \\
\text { foliculares } \\
\text { /COC }\end{array}$ & $\begin{array}{c}\mathrm{N}^{\mathrm{o}} \text { de células } \\
\text { foliculares/campo } \\
\text { de amostragem }\end{array}$ \\
\hline \multirow{3}{*}{$1 \mathrm{a} 4$} & Metaestro & 9 & 20 & 104 & 7 \\
\hline & Diestro & 8 & 24 & 116 & 5 \\
\hline & Proestro & 12 & 20 & 104 & 4 \\
\hline \multirow{3}{*}{4 a 8} & Metaestro & 8 & 14 & 100 & 5 \\
\hline & Diestro & 15 & 20 & 105 & 4 \\
\hline & Proestro & 11 & 20 & 103 & 3 \\
\hline
\end{tabular}



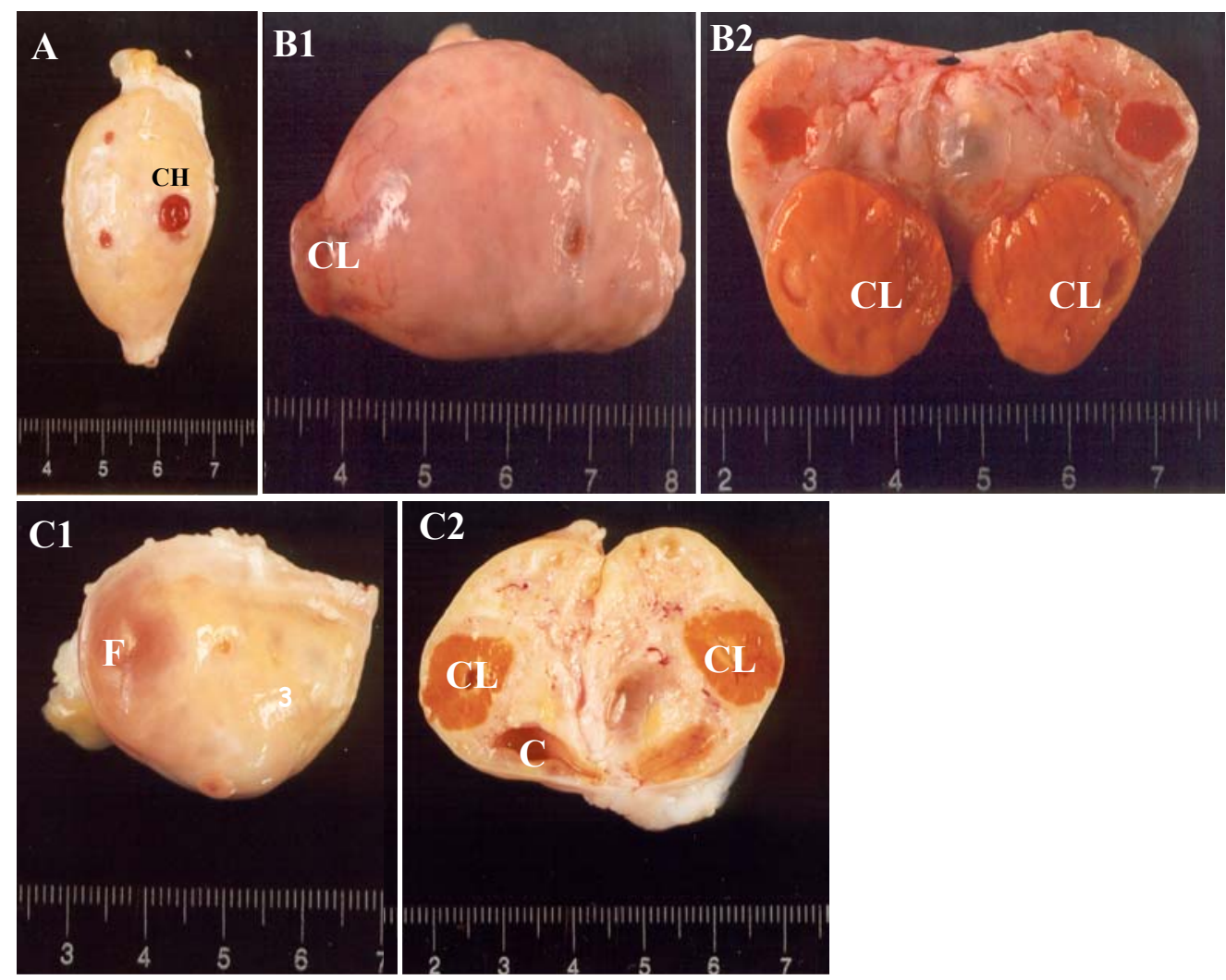

Figura 1. Ovário de Bos taurus em fase de metaestro (A), em fase de diestro, visto de perfil (B1) e em corte (B2), e em fase de proestro, visto de perfil (C1) e em corte $(\mathrm{C} 2)$. Os 17 pares de ovários retirados de animais em metaestro apresentavam corpo hemorrágico $(\mathrm{CH})$ com a superfície vermelha e diâmetro de 0,5 a $1,5 \mathrm{~cm}$. Os 23 pares de ovários em diestro apresentavam corpo lúteo (CL) castanho, laranja ou amarelo, com diâmetro de 1,6 a $2 \mathrm{~cm}$ e vascularização visível ou mesmo proeminente na superfície. Nos 23 pares de ovários em fase de proestro observaram-se vascularização não evidente na superfície do corpo lúteo e presença de pelo menos um folículo de grande dimensão, provavelmente o folículo pré-ovulatório (F). Cavidade do folículo pré-ovulatório (C).

Os COCs foram processados segundo as exigências estereológicas, infiltrados e impregnados com glicol metacrilato (GMA; Historesina, Leica), e cortados em séries de $20 \mu \mathrm{m}$ de espessura em micrótomo automático equipado com faca de tungstênio (Calado et al., 2001, 2003a,b), dos quais obtiveram-se, em média, 12 seções por COC. Elas foram coradas com mistura aquosa $(2: 1)$ de azul de metileno e azur II, e analisadas ao microscópio de luz acoplado a um microcater (com $0,5 \mu \mathrm{m}$ de resolução) para controle do movimento no eixo dos Z, e a uma câmara CCD. O microscópio e o microcater foram ligados a um computador equipado com software Grid para análise estereológica (versão 1.09) (Calado et al., 2001, 2003a,b).

Foi estimada a espessura da ZP total, bem como as porções interna e externa da ZP (Fig. 3A), conforme descrito por Calado et al. (2001, 2003a,b). Os volumes médios dos COCs (Fig. 3B), dos ovócitos com e sem ZP (Fig. 3B), do núcleo dos ovócitos (Fig. 3B) e das células do cumulus (célula e núcleo) (Fig. 4) foram estimados por meio de técnicas estereológicas exatas sem viés, nomeadamente o nucleador (Gundersen, 1988; Gundersen et al., 1988a,b; Bagger, 1993), os dissectores óticos (Howard e Reed, 1998), e grelhas de amostragem de linhas proibidas (Gundersen, 1977). A estratégia 
sistemática uniforme aleatória (Gundersen e Jensen, 1987) foi utilizada nas secções e nos campos de amostragem. Durante a amostragem, a massa do cumulus foi dividida em duas regiões: zona I (primeiras três camadas de células foliculares contadas a partir do ovócito) e zona II (da quarta camada de células foliculares até a periferia do $\mathrm{COC}$ ), sendo também considerada a morfologia das células foliculares (C1, C2 e C3) (Fig. 4A).

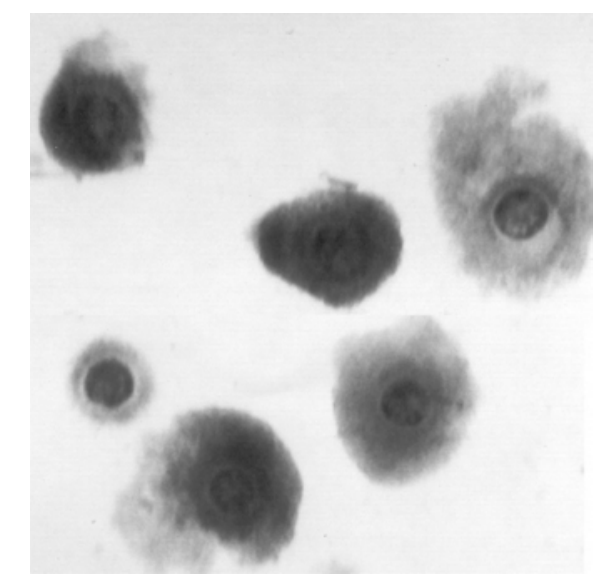

Figura 2. Observação à lupa de complexos cumulus-ovócito de Bos taurus, com massa completa e compacta de cumulus e ooplasma homogêneo ou com finos grânulos periféricos. $40 \times$.

Usou-se o software Statistica e Excel para Windows (Calado et al., 2001, 2003a,b). Os resultados são apresentados como médias, e respectivos erros-padrão das médias, além dos coeficientes de variação por grupo de COCs. Estimaram-se as correlações entre as características e após verificar a normalidade e a homogeneidade das variâncias, os dados das células do cumulus foram agrupados por zona do cumulus, para realizar a análise de variância com dois factores e estudar a interação de efeitos das células do cumulus e do tipo celular com os volumes das células foliculares. Para comparação de médias, usou-se o teste de amplitudes múltiplas de Duncan. A análise de variância também foi usada para estudar as características dos COCs e das células do cumulus ao longo do ciclo estral.

\section{RESULTADOS E DISCUSSÃO}

$\mathrm{Na}$ Fig. 5, estão indicados alguns resultados obtidos da amostragem nas seis categorias de COCs. Apesar de terem sido usados critérios rigorosos para a identificação da fase do ciclo estral (Ireland et al., 1979), para a aspiração dos folículos com o diâmetro pretendido (Lonergan et al., 1994; Carolan et al., 1997), do rígido processo de seleção dos complexos (cumulus compacto e intacto e ooplasma uniforme) (Blondin e Sirard, 1995) e dos cuidados no processamento e na manipulação dos COCs, observou-se grande heterogeneidade relativamente a todas as características estudadas (Calado et al., 2001, 2003a,b). Essa variabilidade pode, em parte, explicar o sucesso obtido na maturação e na fecundação in vitro (Elmileik et al., 1995; Shamsuddin et al., 1996; Shaw e Good, 2000).

Nos folículos antrais médios, o volume médio dos COCs, dos ovócitos com e sem ZP e do núcleo dos ovócitos mantiveram-se inalterados durante todo o ciclo estral (Tab. 2). Contudo, nos pequenos folículos antrais, essas quatro características aumentaram progressivamente do metaestro ao proestro. Entre as duas categorias de diâmetro folicular, observaram-se diferenças significativas relativamente a essa característica durante o metaestro, enquanto que, no período pré-ovulatório (proestro), os valores encontrados não diferiram entre si. Esses resultados traduzem um crescimento acentuado dos complexos e dos respectivos ovócitos nos pequenos folículos antrais, demonstrando que esse crescimento estabiliza-se quando os folículos atingem dimensões de 4 a $8 \mathrm{~mm}$ de diâmetro.

Nos pequenos folículos, observou-se correlação linear entre o volume dos ovócitos e o dos respectivos núcleos durante o metaestro $(\mathrm{r}=0,69$; $\mathrm{P}<0,01)$. Nos folículos médios, verificaram-se correlações lineares entre o volume dos ovócitos e o dos respectivos núcleos no metaestro $(\mathrm{r}=0,93$; $\mathrm{P}<0,001)$, no diestro $(\mathrm{r}=0,85 ; \mathrm{P}<0,001)$ e no proestro $(\mathrm{r}=0,78 ; \mathrm{P}<0,001)$. Esses resultados sugerem que tanto o ovócito quanto o núcleo expandem-se de forma sincronizada apenas depois de o COC atingir uma determinada etapa de crescimento, alcançada no estádio de folículos antrais médios. 

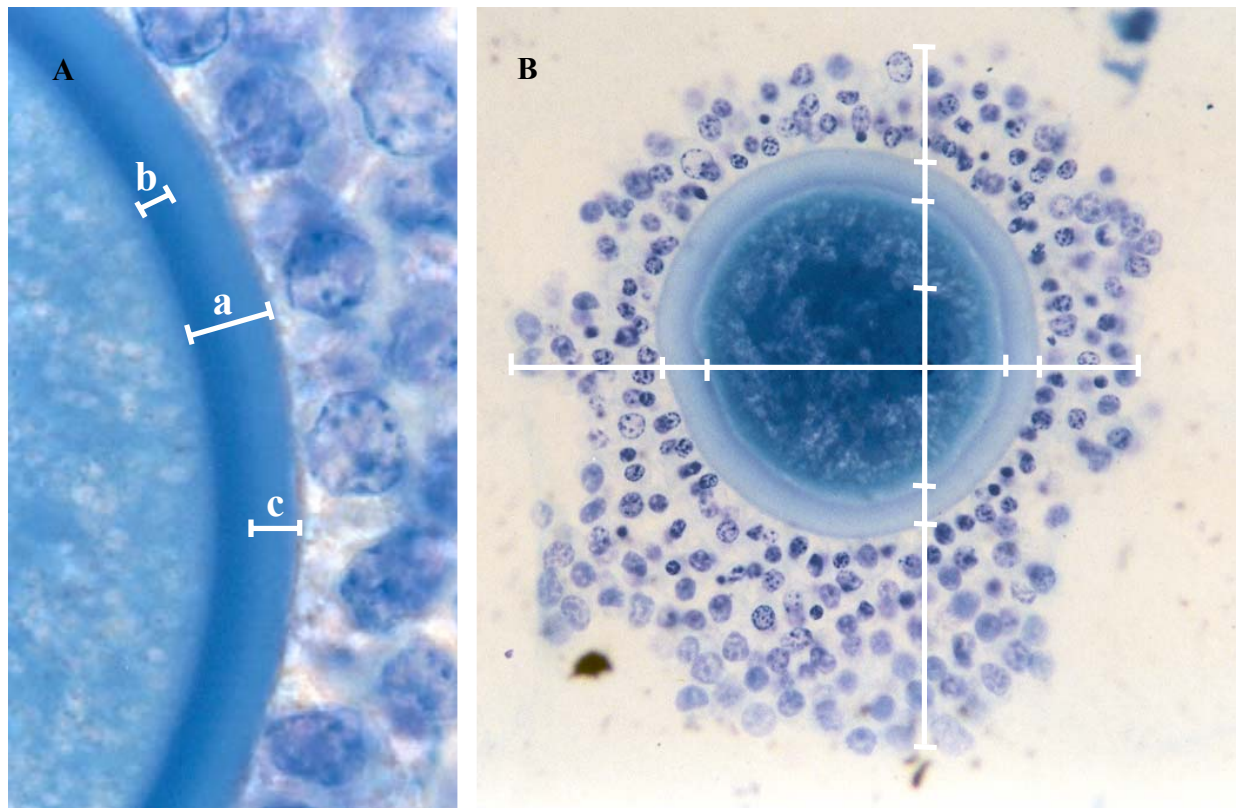

Figura 3. Medição de características-alvo nos complexos cumulus-ovócito (COCs) de Bos taurus.

A- Em cada seção, foram efetuadas duas medições lineares em zonas diametralmente opostas. Efetuaramse três medições, uma interceptando integralmente a ZP (a), e as outras duas restritas às porções interna mais densa (b) e externa mais clara (c) da ZP. Azul de metileno:Azur II (2:1). 1260×. B- Medição do volume de um complexo cumulus-ovócito, do ovócito com e sem ZP, e do núcleo do ovócito, tomando como ponto fixo o centro do nucléolo. Para cada característica amostrada, foi gerada uma direção isotrópica a partir de um ponto aleatório no interior do objeto (em termos práticos, o centro do nucléolo) e mediram-se as distâncias em cada direção a partir de um bordo do núcleo (para estimar o volume nuclear), e/ou do limite celular (para estimar o volume celular). Para efeito de aumento da precisão do volume estimado, utilizou-se a técnica do nucleator four-way (Bagger, 1993), em que as medições foram efetuadas a cada $90^{\circ}$. Azul de metileno:Azur II (2:1). 364×.
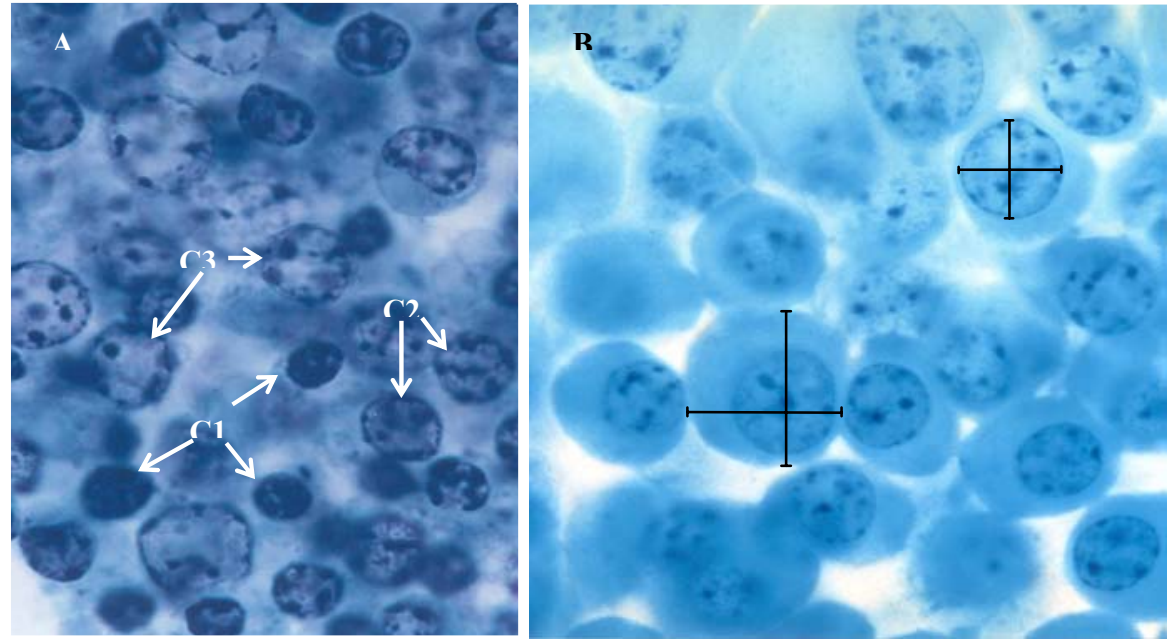

Figura 4. Células foliculares de complexos cumulus-ovócito de Bos taurus. A- Tipos de células foliculares: C1, C2, C3. Azul de metileno:Azur II (2:1). 1400×. B- Medição do volume das células foliculares e dos respectivos núcleos, tomando como ponto fixo o centro virtual do núcleo. Azul de metileno:Azur II (2:1). 1570×. 


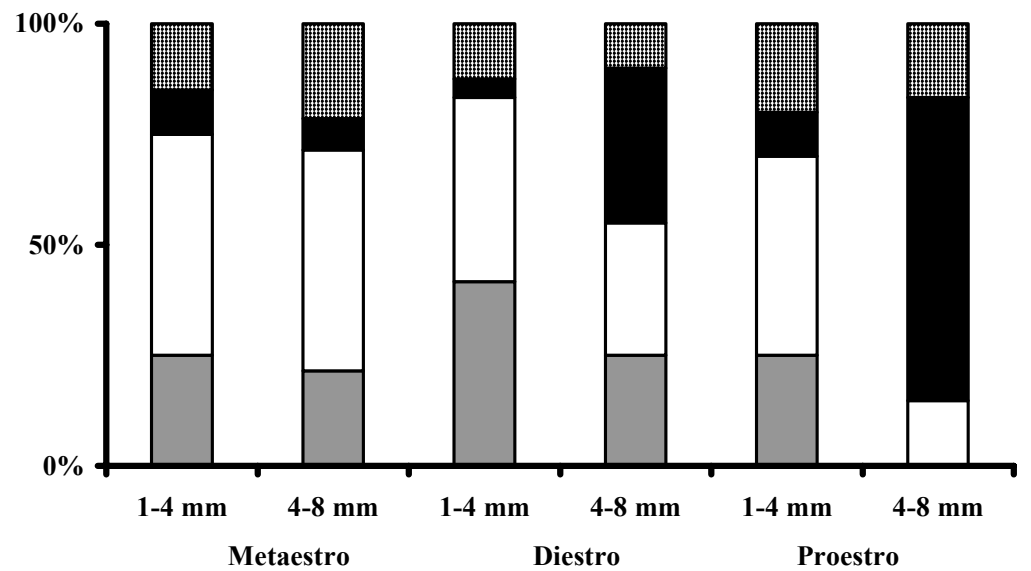

Figura 5. Gráfico ilustrativo da percentagem relativa de complexos cumulus-ovócito com um nucléolo, com vários nucléolos, sem nucléolos e sem núcleo, durante o ciclo estral, em folículos antrais pequenos (1-4mm) e médios (4-8mm) de Bos taurus.

Tabela 2. Volume médio dos complexos cumulus-ovócito (COCs), dos ovócitos com e sem a zona pelúcida (ZP), e dos núcleos dos ovócitos de folículos antrais pequenos (1-4mm) durante o ciclo estral de Bos taurus

\begin{tabular}{|c|c|c|c|c|c|}
\hline Característica & $\begin{array}{c}\text { Diâmetro } \\
\text { folicular }(\mathrm{mm})\end{array}$ & & Metaestro* & Diestro** & Proestro*** \\
\hline \multirow{2}{*}{$\begin{array}{l}\text { Volume médio } \\
\text { dos COCs } \\
\left(\mu \mathrm{m}^{3}\right)\end{array}$} & 1 a 4 & $\begin{array}{l}\text { Média } \\
\text { SEM } \\
\text { CV }\end{array}$ & $\begin{array}{c}19,0 \times 10^{6} \mathrm{a}, \mathrm{A} \\
3,3 \times 10^{6} \\
0,77\end{array}$ & $\begin{array}{c}32,7 \times 10^{6 b} \\
4,5 \times 10^{6} \\
0,68\end{array}$ & $\begin{array}{c}47,6 \times 10^{6} \mathrm{c} \\
5,5 \times 10^{6} \\
0,52\end{array}$ \\
\hline & 4 a 8 & $\begin{array}{l}\text { Média } \\
\text { SEM } \\
\text { CV }\end{array}$ & $\begin{array}{c}47,1 \times 10^{6} \mathrm{~B} \\
10,7 \times 10^{6} \\
0,85\end{array}$ & $\begin{array}{c}28,7 \times 10^{6} \\
4,1 \times 10^{6} \\
0,63\end{array}$ & $\begin{array}{c}40,5 \times 10^{6} \\
4,6 \times 10^{6} \\
0,51\end{array}$ \\
\hline \multirow{2}{*}{$\begin{array}{l}\text { Volume médio } \\
\text { dos ovócitos } \\
\text { com ZP }\left(\mu \mathrm{m}^{3}\right)\end{array}$} & 1 a 4 & $\begin{array}{l}\text { Média } \\
\text { SEM } \\
\text { CV }\end{array}$ & $\begin{array}{c}1,7 \times 10^{6} \mathrm{a}, \mathrm{A} \\
1,0 \times 10^{5} \\
0,27\end{array}$ & $\begin{array}{c}2,2 \times 10^{6} \mathrm{a}, \mathrm{A} \\
3,0 \times 10^{5} \\
0,66\end{array}$ & $\begin{array}{c}3,5 \times 10^{6} \mathrm{~b} \\
3,5 \times 10^{5} \\
0,45\end{array}$ \\
\hline & 4 a 8 & $\begin{array}{l}\text { Média } \\
\text { SEM } \\
\text { CV }\end{array}$ & $\begin{array}{c}3,4 \times 10^{6} \mathrm{~B} \\
7,0 \times 10^{5} \\
0,77\end{array}$ & $\begin{array}{c}3,3 \times 10^{6} \mathrm{C} \\
3,5 \times 10^{5} \\
0,48\end{array}$ & $\begin{array}{c}3,8 \times 10^{6} \\
5,1 \times 10^{6} \\
0,61\end{array}$ \\
\hline \multirow{2}{*}{$\begin{array}{l}\text { Volume médio } \\
\text { dos ovócitos } \\
\text { sem } \mathrm{ZP}\left(\mu \mathrm{m}^{3}\right)\end{array}$} & 1 a 4 & $\begin{array}{l}\text { Média } \\
\text { SEM } \\
\text { CV }\end{array}$ & $\begin{array}{c}1,1 \times 10^{6} \mathrm{a}, \mathrm{A} \\
8,1 \times 10^{5} \\
0,32\end{array}$ & $\begin{array}{c}1,5 \times 10^{6} \mathrm{a}, \mathrm{A} \\
2,3 \times 10^{5} \\
0,76\end{array}$ & $\begin{array}{l}2,6 \times 10^{6} \mathrm{~b} \\
2,7 \times 10^{5} \\
0,47\end{array}$ \\
\hline & 4 a 8 & $\begin{array}{l}\text { Média } \\
\text { SEM } \\
\text { CV }\end{array}$ & $\begin{array}{c}2,4 \times 10^{6} \mathrm{~B} \\
5,3 \times 10^{5} \\
0,85\end{array}$ & $\begin{array}{c}2,5 \times 10^{6} \mathrm{C} \\
3,0 \times 10^{5} \\
0,53\end{array}$ & $\begin{array}{c}3,0 \times 10^{6} \\
4,2 \times 10^{6} \\
0,64\end{array}$ \\
\hline \multirow{2}{*}{$\begin{array}{l}\text { Volume médio } \\
\text { do núcleo dos } \\
\text { ovócitos }\left(\mu \mathrm{m}^{3}\right)\end{array}$} & 1 a 4 & $\begin{array}{l}\text { Média } \\
\text { SEM } \\
\text { CV }\end{array}$ & $\begin{array}{c}27,2 \times 10^{3} \mathrm{a}, \mathrm{A} \\
2,8 \times 10^{4} \\
0,47\end{array}$ & $\begin{array}{c}69,6 \times 10^{3} \mathrm{~b} \\
4,0 \times 10^{4} \\
2,83\end{array}$ & $\begin{array}{c}60,7 \times 10^{3} \mathrm{~b} \\
1,1 \times 10^{4} \\
0,84\end{array}$ \\
\hline & 4 a 8 & $\begin{array}{l}\text { Média } \\
\text { SEM } \\
\text { CV }\end{array}$ & $\begin{array}{c}54,3 \times 10^{3} \mathrm{~B} \\
8,8 \times 10^{3} \\
0,61\end{array}$ & $\begin{array}{c}51,2 \times 10^{3} \\
7,5 \times 10^{3} \\
0,66\end{array}$ & $\begin{array}{c}42,4 \times 10^{3} \\
5,2 \times 10^{3} \\
0,55\end{array}$ \\
\hline
\end{tabular}


A espessura média da ZP e a sua camada externa mantiveram-se constantes durante o ciclo estral nos pequenos folículos antrais, enquanto que nos folículos antrais médios ocorreu redução significativa de metaestro até diestro (Tab. 3). Estes resultados indicam que nos folículos antrais médios, durante o ciclo estral, a compactação da ZP é feita à custa da compactação da sua porção externa. Enquanto que nos folículos antrais médios a espessura média da camada interna da ZP manteve-se constante, nos pequenos folículos antrais essa porção da ZP aumentou do metaestro até o diestro, estabilizando-se até ao final do ciclo estral. Estes resultados indicam compactação extrínseca da ZP, provavelmente devido à alterações moleculares da sua estrutura ou ao aumento da cavidade antral que poderá comprimir a zona pelúcida.

Tabela 3. Espessura média da zona pelúcida (ZP), das regiões interna e externa da ZP dos complexos cumulus-ovóvito (COCs) de folículos antrais pequenos $(1-4 \mathrm{~mm})$ e médios $(4-8 \mathrm{~mm})$ durante o ciclo estral de Bos taurus

\begin{tabular}{|c|c|c|c|c|c|}
\hline Característica & $\begin{array}{c}\text { Diâmetro } \\
\text { folicular }(\mathrm{mm})\end{array}$ & & Metaestro* & Diestro** & Proestro*** \\
\hline \multirow{6}{*}{$\begin{array}{l}\text { Espessura } \\
\text { média da } \\
\mathrm{ZP}(\mu \mathrm{m})\end{array}$} & & Média & $7,9 \mathrm{~A}$ & 8,5 & 8,2 \\
\hline & 1 a 4 & SEM & 0,3 & 0,6 & 0,5 \\
\hline & & $\mathrm{CV}$ & 0,15 & 0,32 & 0,27 \\
\hline & & Média & $10,8 \mathrm{a}, \mathrm{B}$ & $8,0 \mathrm{~b}$ & $6,9 b$ \\
\hline & 4 a 8 & SEM & 0,2 & 0,3 & 0,3 \\
\hline & & $\mathrm{CV}$ & 0,34 & 0,18 & 0,17 \\
\hline \multirow{6}{*}{$\begin{array}{l}\text { Espessura média da } \\
\text { Camada interna } \\
\text { da ZP }(\mu \mathrm{m})\end{array}$} & & Média & $2,3 a$ & $2,8 b$ & $3,0 \mathrm{~b}$ \\
\hline & $1 \mathrm{a} 4$ & SEM & 0,3 & 0,2 & 0,1 \\
\hline & & $\mathrm{CV}$ & 0,49 & 0,33 & 0,34 \\
\hline & & Média & 2,4 & 2,5 & 2,5 \\
\hline & 4 a 8 & SEM & 0,3 & 0,2 & 0,3 \\
\hline & & $\mathrm{CV}$ & 0,48 & 0,27 & 0,47 \\
\hline \multirow{6}{*}{$\begin{array}{l}\text { Espessura média da } \\
\text { camada externa } \\
\text { da } Z \mathrm{P}(\mu \mathrm{m})\end{array}$} & & Média & $6,0 \mathrm{~A}$ & 5,6 & 5,8 \\
\hline & 1 a 4 & SEM & 0,3 & 0,4 & 0,2 \\
\hline & & $\mathrm{CV}$ & 0,21 & 0,34 & 0,38 \\
\hline & & Média & $8,7 \mathrm{a}, \mathrm{B}$ & $5,5 b$ & $5,0 \mathrm{~b}$ \\
\hline & 4 a 8 & SEM & 0,9 & 0,2 & 0,2 \\
\hline & & $\mathrm{CV}$ & 0,37 & 0,19 & 0,17 \\
\hline
\end{tabular}

SEM= erro-padrão da média. Para espessura média da ZP: *estimativa para 20 e 14 COCs em folículos de 1-4 e de 4-8mm, respectivamente; **estimativa para 24 e 20 COCs em folículos de $1-4$ e de $4-8 \mathrm{~mm}$, respectivamente; ***estimativa para 20 COCs; valores com diferentes letras minúsculas e maiúsculas na linha e na coluna, respectivamente, diferem entre si $(\mathrm{P}<0,001)$.

Para espessura média da porção interna da ZP: *estimativa para 15 e 12 COCs em folículos de 1-4 e de 4-8mm, respectivamente; **estimativa para 24 e 19 COCs em folículos de $1-4$ e de $4-8 \mathrm{~mm}$, respectivamente; ***estimativa para 13 e 12 COCs em folículos de 1-4 e de 4-8mm, respectivamente; valores com diferentes letras minúsculas na linha diferem entre si $(\mathrm{P}<0,05)$.

Para espessura média da porção externa da ZP: *estimativa para 20 e 14 COCs em folículos de 1-4 e de 4-8mm, respectivamente; ** estimativa para 24 e 19 COCs em folículos de $1-4$ e de 4-8mm, respectivamente; *** estimativa para 13 e 12 COCs em folículos de 1-4 e de 4-8mm, respectivamente; valores com diferentes letras minúsculas e maiúsculas na linha e na coluna, respectivamente, diferem entre si $(\mathrm{P}<0,001)$.

Tomando em conjunto a análise do volume dos COCs, dos ovócitos e dos núcleos dos ovócitos, e a espessura da ZP, os resultados indicaram que os folículos antrais imaturos de $1-4 \mathrm{~mm}$ apresentaram crescimento acelerado e sem sincronia entre o aumento de volume do citoplasma e o do núcleo. Os folículos antrais de 4-8mm, pelo contrário, apresentaram desaceleração do crescimento, observando-se expansão harmoniosa núcleo-citoplasmática. Provavelmente, essa alteração do padrão de crescimento pode estar relacionada com a divergência ou seleção folicular que ocorre quando o folículo líder (futuro folículo dominante) atinge cerca de $8,5 \mathrm{~mm}$ e o maior folículo subordinado tem o diâmetro aproximado 
a 7,2mm (Ginther et al., 1996, 2001).

Em cada uma das seis classes de COCs estudadas, foram identificadas três populações de células foliculares: $\mathrm{C} 1, \mathrm{C} 2$ e $\mathrm{C} 3$, sendo $\mathrm{C} 1$ a menos volumosa (núcleos muito densos), $\mathrm{C} 2$ a de volume intermédio (núcleo de densidade intermédia) e $\mathrm{C} 3$ a mais volumosa (núcleos pálidos). Ao longo do ciclo estral, o volume médio das células $\mathrm{C} 1$ foi similar nos folículos antrais médios, enquanto que nos pequenos folículos ocorreu hipertrofia significativa das células de diestro para proestro (Tab. 4). Relativamente ao volume médio do núcleo das células $\mathrm{C} 1$, são se observaram alterações significativas durante o ciclo estral em ambas as categorias de diâmetros foliculares. Quanto às células tipo $\mathrm{C} 2$ e $\mathrm{C} 3$, o volume médio das células e o dos respectivos núcleos permaneceram inalterados durante o ciclo estral nos folículos antrais médios, enquanto que nos pequenos folículos antrais foi observada hipertrofia significativa desde o diestro até o proestro. $\mathrm{O}$ volume das células $\mathrm{C} 2$ e $\mathrm{C} 3$ foi sempre superior nos folículos antrais médios durante o período de metaestro; não se observaram diferenças significativas entre as duas categorias de diâmetro folicular durante o proestro. Estes resultados indicam que o crescimento das células foliculares predomina na fase pré-ovulatória dos pequenos folículos, momento em que os volumes celular e nuclear das duas categorias de diâmetros foliculares se igualam.

A freqüência numérica relativa dos três tipos celulares nas seis classes de complexos está condensada na Tab. 5. Pode-se encontrar a mesma freqüência numérica relativa nas regiões próximas ou afastadas do ovócito, pois os resultados apresentados referem-se à massa de cumulus total para as seis classes de COCs. Observa-se que a freqüência numérica relativa dos três tipos celulares na massa de cumulus depende apenas do tipo celular e tanto a região do cumulus quanto a interação tipo celular versus cumulus não exerceram efeito sobre a freqüência numérica relativa.

Tabela 4. Volume médio dos tipos celulares $\mathrm{C} 1, \mathrm{C} 2$ e $\mathrm{C} 3$ e dos respectivos núcleos ao longo do ciclo estral de Bos taurus

\begin{tabular}{|c|c|c|c|c|c|c|c|c|}
\hline \multirow{3}{*}{$\begin{array}{l}\text { Tipo } \\
\text { celular }\end{array}$} & \multirow{3}{*}{$\begin{array}{c}\text { Diâmetro } \\
\text { folicular } \\
(\mathrm{mm})\end{array}$} & & \multicolumn{6}{|c|}{ Volumes médios celular e nuclear $\left(\mathrm{mm}^{3}\right)$ durante o ciclo estral } \\
\hline & & & \multicolumn{2}{|c|}{ Metaestro } & \multicolumn{2}{|c|}{ Diestro } & \multicolumn{2}{|c|}{ Proestro } \\
\hline & & & Célula & Núcleo & Célula & Núcleo & Célula & Núcleo \\
\hline \multirow{6}{*}{$\mathrm{C} 1$} & \multirow{3}{*}{1 a 4} & Média & $474,3 a$ & 102,2 & $550,6 a$ & 107,6 & $1103,2 b$ & 254,8 \\
\hline & & SEM & 58,8 & 10,7 & 50,7 & 13,0 & 101,6 & 22,4 \\
\hline & & $\mathrm{CV}$ & 0,55 & 0,46 & 0,38 & 0,50 & 0,41 & 0,39 \\
\hline & \multirow{3}{*}{4 a 8} & Média & 745,3 & 146,6 & 597,4 & 125,8 & 513,7 & 140,6 \\
\hline & & SEM & 82,8 & 23,8 & 55,3 & 12,2 & 21,8 & 6,0 \\
\hline & & $\mathrm{CV}$ & 0,42 & 0,61 & 0,41 & 0,43 & 0,19 & 0,19 \\
\hline \multirow{6}{*}{$\mathrm{C} 2$} & \multirow{3}{*}{1 a 4} & Média & $646,7 \mathrm{a}, \mathrm{A}$ & $196,6 \mathrm{c}, \mathrm{A}$ & $807,2 \mathrm{a}, \mathrm{A}$ & $200,2 \mathrm{c}, \mathrm{A}$ & $1875,8 b$ & $608,8 \mathrm{~d}$ \\
\hline & & SEM & 70,9 & 20,4 & 66,6 & 18,5 & 150,1 & 60,9 \\
\hline & & $\mathrm{CV}$ & 0,49 & 0,46 & 0,34 & 0,38 & 0,36 & 0,45 \\
\hline & \multirow{3}{*}{4 a 8} & Média & 1118,1B & $344,4 \mathrm{~B}$ & $1354,1 \mathrm{~B}$ & $435,9 \mathrm{~B}$ & 1267,5 & 425,4 \\
\hline & & SEM & 128,5 & 50,3 & 151,7 & 56,7 & 126,1 & 55,7 \\
\hline & & $\mathrm{CV}$ & 0,40 & 0,55 & 0,50 & 0,58 & 0,44 & 0,59 \\
\hline \multirow{6}{*}{$\mathrm{C} 3$} & \multirow{3}{*}{$1 \mathrm{a} 4$} & Média & $1051,8 \mathrm{a}, \mathrm{A}$ & $420,7 \mathrm{c}, \mathrm{A}$ & $1546,8 \mathrm{a}, \mathrm{A}$ & $604,6 \mathrm{c}, \mathrm{A}$ & $2748,4 b$ & $1029,2 \mathrm{~d}$ \\
\hline & & SEM & 99,6 & 38,1 & 180,1 & 93,8 & 190,7 & 74,8 \\
\hline & & $\mathrm{CV}$ & 0,42 & 0,40 & 0,48 & 0,64 & 0,31 & 0,32 \\
\hline & \multirow{3}{*}{4 a 8} & Média & $1803,4 \mathrm{~B}$ & $666,1 \mathrm{~B}$ & $1983,8 \mathrm{~B}$ & $776,1 \mathrm{~B}$ & 2395,2 & 990,4 \\
\hline & & SEM & 168,7 & 77,2 & 145,3 & 64,1 & 228,2 & 88,9 \\
\hline & & $\mathrm{CV}$ & 0,35 & 0,43 & 0,33 & 0,37 & 0,43 & 0,40 \\
\hline
\end{tabular}

$\widehat{\mathrm{SEM}}=$ erro-padrão da média. Para células foliculares tipo $\mathrm{C} 1$ : valores com diferentes letras minúsculas na linha diferem entre si $(\mathrm{P} \leq 0,05)$. Para células foliculares tipo $\mathrm{C} 2$ : valores com diferentes letras minúsculas na linha diferem entre si: a $v s . \mathrm{b}(\mathrm{P} \leq 0,001) ; \mathrm{c} v s$. d $(\mathrm{P} \leq 0,05)$. Valores com diferentes letras maiúsculas na coluna diferem entre si $(\mathrm{P} \leq 0,05)$. Para células foliculares tipo $\mathrm{C} 3$ : valores com diferentes letras minúsculas na linha diferem entre si: a vs. b, c vs. d (P $\leq 0,001)$. Valores com diferentes letras maiúsculas na coluna diferem entre si $(\mathrm{P} \leq 0,05)$. 
Estudo estereológico comparativo de complexos cumulus-ovócito...

Tabela 5. Percentagem numérica relativa (\%) dos tipos de células foliculares $\mathrm{C} 1, \mathrm{C} 2$ e $\mathrm{C} 3$ nos complexos cumulus-ovócitos de Bos taurus ao longo do ciclo estral

\begin{tabular}{|c|c|c|c|c|c|}
\hline \multirow{2}{*}{$\begin{array}{l}\text { Tipo } \\
\text { celular }\end{array}$} & \multirow{2}{*}{$\begin{array}{c}\text { Diâmetro } \\
\text { folicular }(\mathrm{mm})\end{array}$} & & \multicolumn{3}{|c|}{ Percentagem numérica relativa (\%) durante o ciclo estral } \\
\hline & & & Metaestro & Diestro & Proestro \\
\hline \multirow{6}{*}{$\mathrm{C} 1$} & \multirow{3}{*}{1 a 4} & Média & $27,5 \mathrm{a}$ & $15,7 \mathrm{~b}, \mathrm{~A}$ & $1,5 \mathrm{c}$ \\
\hline & & SEM & 2,3 & 3,0 & 0,6 \\
\hline & & $\mathrm{CV}$ & 0,38 & 0,79 & 1,96 \\
\hline & \multirow{3}{*}{4 a 8} & Média & $23,7 \mathrm{a}$ & $2,9 \mathrm{c}, \mathrm{B}$ & $3,3 \mathrm{c}$ \\
\hline & & SEM & 5,6 & 1,5 & 1,8 \\
\hline & & $\mathrm{CV}$ & 0,89 & 2,40 & 2,43 \\
\hline \multirow{6}{*}{$\mathrm{C} 2$} & \multirow{3}{*}{1 a 4} & Média & 45,1 & $32,4 \mathrm{~A}$ & $38,0 \mathrm{~A}$ \\
\hline & & SEM & 2,8 & 4,2 & 4,3 \\
\hline & & $\mathrm{CV}$ & 0,28 & 0,53 & 0,51 \\
\hline & \multirow{3}{*}{4 a 8} & Média & $36,7 \mathrm{a}$ & $19,9 \mathrm{~b}, \mathrm{~B}$ & $7,5 \mathrm{c}, \mathrm{C}$ \\
\hline & & SEM & 1,5 & 4,2 & 3,7 \\
\hline & & $\mathrm{CV}$ & 0,15 & 0,94 & 2,23 \\
\hline \multirow{6}{*}{$\mathrm{C} 3$} & \multirow{3}{*}{1 a 4} & Média & $27,4 a, A$ & $51,9 \mathrm{c}, \mathrm{A}$ & $60,6 \mathrm{c}, \mathrm{A}$ \\
\hline & & SEM & 4,2 & 6,4 & 4,6 \\
\hline & & $\mathrm{CV}$ & 0,69 & 0,51 & 0,34 \\
\hline & \multirow{3}{*}{4 a 8} & Média & $39,6 \mathrm{a}, \mathrm{B}$ & $77,2 \mathrm{~b}, \mathrm{C}$ & $89,2 \mathrm{c}, \mathrm{C}$ \\
\hline & & SEM & 4,9 & 4,9 & 4,9 \\
\hline & & $\mathrm{CV}$ & 0,46 & 0,28 & 0,24 \\
\hline
\end{tabular}

$\overline{\mathrm{SEM}}=$ erro-padrão da média. Para células foliculares tipo $\mathrm{C} 1$ : valores com diferentes letras minúsculas na linha diferem entre si: a vs. b, b vs. c $(\mathrm{P} \leq 0,05)$; a vs. c $(\mathrm{P} \leq 0,001)$; valores com diferentes letras maiúsculas na coluna diferem entre si $(\mathrm{P} \leq 0,05)$.

Para células foliculares tipo $\mathrm{C} 2$ : valores com diferentes letras minúsculas na linha diferem entre si: a $v s . \mathrm{b},(\mathrm{P} \leq 0,01)$; b vs. c, a $v s$. c $(\mathrm{P} \leq 0,001)$; valores com diferentes letras maiúsculas na coluna diferem entre si: $\mathrm{A}$ vs. $\mathrm{B}(\mathrm{P} \leq 0,05)$; $\mathrm{A}$ vs. $\mathrm{C}(\mathrm{P} \leq 0,01)$.

Para células foliculares tipo $\mathrm{C} 3$ : valores com diferentes letras minúsculas na linha diferem entre si: a vs. c $(\mathrm{P} \leq 0,001)$; a vs. $\mathrm{b}, \mathrm{b}$ vs. $\mathrm{c}$ $(\mathrm{P} \leq 0,05)$; valores com diferentes letras maiúsculas na coluna diferem entre si: $\mathrm{A}$ vs. $\mathrm{B}(\mathrm{P} \leq 0,05) ; \mathrm{A}$ vs. $\mathrm{C}(\mathrm{P} \leq 0,01)$.

Quanto à freqüência de células tipo $\mathrm{C} 1$, observou-se redução significativa e constante delas durante o ciclo estral nos pequenos folículos antrais, enquanto que nos folículos médios a redução estabilizou-se a partir da fase lútea (diestro). No estudo da freqüência relativa das células $\mathrm{C} 2$, houve redução significativa dos folículos médios durante o ciclo, enquanto que nos pequenos folículos antrais a percentagem de distribuição não se alterou. Nos pequenos folículos antrais a distribuição do tipo celular $\mathrm{C} 2$ foi significativamente superior durante o diestro e o proestro (Tab. 5). Quanto à freqüência relativa das células do tipo $\mathrm{C} 3$, observou-se aumento significativo delas durante todo o ciclo estral nos folículos antrais médios, e aumento significativo na percentagem de células $\mathrm{C} 3$ de metaestro para diestro, seguida de estabilização, nos pequenos folículos. Além disso, o número de células $\mathrm{C} 3$ foi sempre significativamente maior nos folículos antrais médios.

Os pequenos folículos antrais são caracterizados por constante redução no número de células $\mathrm{C} 1 \mathrm{e}$ aumento de células $\mathrm{C} 3$ de metaestro para diestro, mantendo inalterada a população de células $\mathrm{C} 2$. Os folículos antrais médios são caracterizados pela diminuição constante das células $\mathrm{C} 2$ e pelo aumento das células $\mathrm{C} 3$, enquanto que o número de células $\mathrm{C} 1$ diminui de metaestro para diestro, e estabiliza-se até a ovulação. No entanto, a comparação entre as duas categorias de folículos mostra que em ambos a diminuição da percentagem de células $\mathrm{C} 1$ é similar, embora mais lenta e progressiva nos pequenos folículos, e mais rápida nos folículos antrais médios. Isto é, ambas as categorias de diâmetros foliculares apresentam o mesmo grau de desaparecimento de células foliculares tipo $\mathrm{C}$ 1. Um fenômeno semelhante foi detectado com as células tipo $\mathrm{C} 3$, cuja percentagem relativa aumentou de forma lenta e progressiva nos folículos antrais médios, e abruptamente nos pequenos folículos antrais, verificando-se, no entanto, sempre maior percentagem relativa de células de tipo C3 nos primeiros. Verifica-se, assim, um gradiente contínuo em que as células $\mathrm{C} 1$ são progressivamente substituídas pelas de tipo $\mathrm{C} 2$, e 
estas finalmente pelas células de tipo C3. Estas últimas constituem a população de células foliculares predominantes durante o período préovulatório. Essa descoberta vem alterar os conceitos atuais da fisiologia folicular, pois demonstra que as células foliculares, ao contrário dos ovócitos, respondem aos níveis circulantes de hormônios, demonstrando maturação celular, estrutural e funcional completa ao longo do ciclo estral, apesar de se encontrarem em um folículo antral imaturo. A dissociação observada entre as células foliculares e o ovócito pode ser explicada pela incompetência do citoplasma do ovócito no processo de maturação, provavelmente por redução de expressão e, conseqüentemente, da estrutura dos organelos e da acumulação de $\mathrm{RNAs}_{\mathrm{m}}$ necessários para o ovócito apresentar capacidade fecundante e de manter o desenvolvimento embrionário. A capacidade de resposta das células foliculares dos folículos antrais médios foi sempre superior, como demonstrado pelo redução no número de células C1 e C2 face ao aumento das células C3. Pelo contrário, os folículos pequenos, apesar de evidenciarem o mesmo padrão de diferenciação, apresentam uma limitação desse padrão, como se constata pela manutenção do número de células $\mathrm{C} 2$ e pelo aumento do número de $\mathrm{C} 3$, o que comprova estarem em uma etapa de menor capacidade evolutiva.

\section{REFERÊNCIAS BIBLIOGRÁFICAS}

BAGGER, P.V.; BANG, L.; CHRISTIANSEN, M.D. et al. Classification of isolated ovarian follicles using the nucleator: estimation of antral volume. Acta Stereol., v.8, p.123-126, 1989.

BAGGER, P.V.; BANG, L.; CHRISTIANSEN, M.D. et al. Total number of particles in a bounded region estimated directly with the nucleator: granulosa cell number in ovarian follicles. Am. J. Obstetr. Gynecol., v.168, p.724-731, 1993.

BAGGER, V. Direct estimation of volumes in ovarian follicles using the nucleator. Acta Pathol. Microbiol. Immunol. Scand., v.101, p.784-790, 1993.

BLONDIN, P.; SIRARD, M.A. Oocyte and follicular morphology as determining characteristics for developmental competence in bovine oocytes. Mol. Reprod. Dev., v.41, p.54-62, 1995.

CALADO, A.M.; ROCHA, E.; COLAÇ, A. et al. Stereological characterization of bovine (Bos taurus) cumulus-oocyte complexes aspirated from small antral follicles during the diestrous phase. Biol. Reprod., v.65, p.1383-1391, 2001.

CALADO, A.M.; ROCHA, E.; COLAÇO, A. et al. Stereological characterization of bovine (Bos taurus) cumulus-oocyte complexes aspirated from small antral follicles during the metestrous and proestrous phases. Theriogenology, v.60, p.429-443, 2003a.

CALADO, A.M.; ROCHA, E.; COLAÇO, A. et al. Stereological characterization of bovine (Bos taurus) cumulus-oocyte complexes aspirated from medium antral follicles during the estrous cycle. Tiss. Cell, v.35, p.313-323, 2003b.

CAROLAN, C.; LONERGAN, P.; MONGET, P. et al. Effect of follicle size and quality on the ability of follicular fluid to support cytoplasmic maturation of bovine oocytes. Mol. Reprod. Dev., v.43, p.477-483, 1997.

DE LOOS, F.; KASTROP, P.; VAN MAURIK, P. et al. Heterolougous cell contacts and metabolic coupling in bovine cumulus oocyte complexes. Mol. Reprod. Dev., v.28, p.255-259, 1991.

DE LOOS, F.; VAN VLIET, C.; VAN MAURIK, P. et al. Morphology of immature bovine oocytes. Gamete Res., v.24, p.197-204, 1989.

DHAR, A.; DOCKERY, P.; TURNER, K. et al. The human ovarian granulosa cell: a stereological approach. J. Anat., v.188, p.671-676, 1996.

ELMILEIK, A.M.A.; MAEDA, T.; TERADA, T. Higher rates of development into blastocyst following the in vitro fertilization of bovine oocytes matured in a medium supplemented with the follicular fluid from large bovine follicles. Anim. Reprod. Sci., v.38, p.8596, 1995.

GINTHER, O.J.; BEG, M.A.; BERGFELT, D.R. et al. Follicle selection in monovular species. Biol. Reprod., v.65, p.638-647, 2001.

GINTHER, O.J.; WILTBANK, H.C.; FRICKE, P.M. et al. Selection of the dominant follicle in cattle. Biol. Reprod., v.55, p.1187-1194, 1996.

GUNDERSEN, H.J.B.; JENSEN, E.B. The efficiency of systematic sampling in stereology and its prediction. J. Microsc., v.147, p.229-263, 1987.

GUNDERSEN, H.J.G. Notes on the estimation of the numerical density of arbitrary profiles: the edge effect. J. Microsc., v.111, p.219-223, 1977.

GUNDERSEN, H.J.G. The nucleator. J. Microsc., v.151, p.3-21, 1988.

GUNDERSEN, H.J.G.; BAGGER, P.; BENDTSEN, T.F. et al. The new stereological tools: disector, fractionator, nucleator and point sampled intercepts and their use in pathological research and diagnosis. 
Acta Pathol. Microbiol. Immunol. Scand., v.96, p.857$881,1988 \mathrm{a}$

GUNDERSEN, H.J.G.; BENDTSEN, T.F.; KORBO, L. et al. Some new, simple and efficient stereological methods and their use in pathological research and diagnosis. Acta Pathol. Microbiol. Immunol. Scand., v.96, p.379-394, 1988 b.

HAZELEGER, N.L.; STUBBINGS, R.B. Developmental potential of selected bovine oocyte cumulus complexes. Theriogenology, v.37, p.219, 1992.

HOWARD, C.V.; REED, M.G. Unbiased stereology Three-dimensional measurement in microscopy. Microscopy Handbook Series, 41. Oxford, UK: Bios Scientific Publishers, 1998.

IRELAND, J.J.; COULSON, P.B.; MURPHER, R.L. Follicular development during four stages of the estrous cycle of beef cattle. J. Anim. Sci., v.49, p.12611269, 1979.

LEIBFRIED, L.; FIRST, N.L. Characterization of bovine follicular oocytes and their ability to mature in vitro. J. Anim. Sci., v.48, p.76-86, 1979.
LONERGAN, P.; MONAGHAN, P.; RIZOS, D. et al. Effect of follicle size on bovine oocyte quality and developmental competence following maturation, fertilization, and culture in vitro. Mol. Reprod. Dev., v.37, p.48-53, 1994.

LUNDY, T.; SMITH, P.; O'CONNELL, A. et al. Populations of granulosa cells in small follicles of the sheep ovary. J. Reprod. Fertil., v.115, p.251-262, 1999.

MADISON, V.; AVERY, B.; GREVE, T. Selection of immature bovine oocytes for developmental potential in vitro. Anim. Reprod. Sci., v.27, p.1-11, 1992.

MILLER, P.B.; CHARLESTON, J.S.; BATTAGLIA, D.E. et al. An accurate, simple method for unbiased determination of primordial follicle number in the primate ovary. Biol. Reprod., v.56, p.909-915, 1997.

SHAMSUDDIN, M.; NIWA, K.; LARSSON, B. et al. Review: In vitro maturation and fertilization of bovine oocytes. Reprod. Dom. Anim., v.31, p.613-622, 1996.

SHAW, D.W.; GOOD, T.E. Recovery rates and embryo quality following dominant follicle ablation in superovulated cattle. Theriogenology, v.63, p.513-518, 2000. 